\title{
Solving a Sequence of Recurrence Relations for First-Order Differential Equations
}

\author{
Andrey Batukhtin ${ }^{1 *}$, Irina Batukhtina ${ }^{1}$, Maxim Bass ${ }^{1}$, Sergey Batukhtin ${ }^{1}$, Pavel Safronov ${ }^{1}$, \\ Marina Baranovskaya ${ }^{1}$ \\ ${ }^{1}$ Transbaikal State University, RUSSIA
}

Received 8 April 2017 - Revised 3 September 2017 • Accepted 25 September 2017

\begin{abstract}
A whole category of engineering and economic problems can be reduced to solving a set of differential equations. Downsides of known approaches for their solutions include limited accuracy numerical methods with stringent requirements for computational power. A direct analytical solution should be derived to eliminate such flaws. This research intends to derive such a solution for an $n$-dimensional set of recurrence relations for first-order differential equations, linearly dependent on the right side. The research methodology relies on successive integration of the considered set in view of the initial conditions. The overall solution was derived as a sum of products of exponential multipliers with constant coefficients that are defined through weights of a tree graph, which is a descriptor of successive integration. An analytical solution for an $n$-dimensional set of recurrent differential equations in view of the initial conditions has been derived for the first time in this research.
\end{abstract}

Keywords: analytical condition, differential equations, differentiation, initial conditions

\section{INTRODUCTION}

A whole category of engineering and economic problems (heat engineering, transport, information, technical and economic optimization problems, etc.) can be reduced to a set of recurrence relations of first-order differential equations, linearly dependent on the right side.

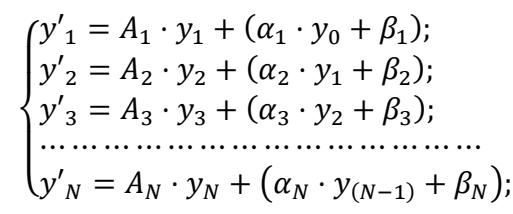

where:

$$
A_{1}, \ldots, A_{N}, \alpha_{1}, \ldots, \alpha_{N}, \beta_{1}, \ldots, \beta_{N} \text { are constants; } y_{1}^{\prime}, \ldots, y_{N}^{\prime} \text { are first-degree derivatives, that is, } \frac{d y_{1}}{d x}, \ldots, \frac{d y_{N}}{d x} .
$$

These problems include thermodynamic analysis models (Sheng \& Tu, 2013; Bolatturk, 2006; Kalema et al., 2008; Stepanov et al., 2000; Valero, 2014; Torío et al., 2009; Romero \& Linares, 2014), heat power system models (Goryachikh et al., 2010; Kicsiny, 2014; Bau et al., 2015; Kicsiny, 2017), combustion models (Messerle et al., 2013; Messerle et al., 2014; Messerle et al., 2016; ; Messerle et al., 2016; Gao et al., 2010; Karpenko et al., 2016), local heat exchange system models (e.g., solar collectors (Kaminski \& Krzyzynski, 2016; Hussain et al., 2016; Bég et al., 2016; Li \& Chen, 2008; Smith et al., 2012; Thianpong et al., 2012), etc.

Sets of homogeneous and non-homogeneous differential equations are currently one of the basic tools for mathematical modeling of physical processes (Kicsiny, 2014). A set of homogeneous differential equations for adsorption chiller control is discussed by Bau et al. (2015). A solution is considered as a gradient process and no direct linear dependence is given. Richard Kicsiny discusses modern mathematical models of a piped heat system

\footnotetext{
(C) Authors. Terms and conditions of Creative Commons Attribution 4.0 International (CC BY 4.0) apply. $\square$ batukhtin.1982@mail.ru (*Correspondence) $\square$ batukhtina-78@mail.ru $\square$ MBass77@yandex.ru 


\section{Contribution of this paper to the literature}

- In contrast to the known methods for solving systems of first-order differential equations, this article has obtained a direct analytic dependence for the $\mathrm{n}$-dimensional system.

- The resulting solution is easily integrated and differentiated, since it has only exponential coefficients.

- The resulting solution can be used in more complex mathematical models of physical processes as an integral part.

- The given example of a solution for the n-dimensional system of cooling sections of a heat network showed the simplicity of applying a direct analytical solution.

in his latest studies (Kicsiny, 2014; Kicsiny, 2017) based on differential equations of the Newton's law for pipe cooling. A rather common problem is building dynamic models of municipal heat networks to improve their efficiency. These usually rely on a set of differential equations and their solution is reduced to numerical solutions (Kicsiny, 2016; Stevanovic et al., 2009). Alternatively, a significant simplification of the model is considered via one or two equations for mean parameters, which are then solved using known dependences (Polyanin \& Zaitsev, 2003).

Sets of homogeneous and non-homogeneous differential equations underlie the theory to describe combustion processes. For example, sets of differential equations with hundreds of such equations are made when building reliable mathematical models of gasification of solid fuel particles (Karpenko \& Trusov, 1995). These sets are usually reduced by the finite-difference method to trivial equations, which leads to a relative loss of accuracy and no direct analytical solutions exist (Messerle et al., 2016).

The increasing use of non-conventional and recoverable sources of energy in the world shaped a separate branch of the theory of mathematical modeling of solar collector operations. Modeling of solar collectors is usually reduced to solving individual differential equations or sets of such equations. Kicsiny improved multiple linear regressions for solving differential equations that simulate a solar collector (Kicsiny, 2016). Kaminski \& Krzyzynski presented a numerical and experimental study of a flat solar collector (Kaminski \& Krzyzynski, 2016). At the same time, hydrodynamics and heat exchange in the collector panel are defined by transforming differential equations using the finite-difference method. Saleh et al. described a mathematical model for modeling transient processes occurring in the heated fluid of a flat collector (Saleh, 2015). This model relies on a solution of a set of linked differential equations describing heat processes of glazing, air gap, fluid, etc. The set of differential solutions is solved iteratively in the MATLAB environment. Most modeling problems are reduced to a numerical solution of a set of differential equations in this or similar system (Etter et al., 2004). Modeling projects of hybrid solar photoelectric heat systems (based on numerical solutions) can serve as an example of such studies (Khelifa et al., 2016; Gholampour \& Ameri, 2015; Khelifa et al., 2015). The major drawback of such numerical solutions is that they cannot be used in more complex models.

Main downsides of known approaches to solving single differential equations or sets of such equations in applied mathematical modeling problems for physical processes are discussed in the next section. This discussion is followed by deriving a direct analytical solution of a set of recurrence relations for first-order differential equations in view of the initial conditions and by using successive integration. Then, this study considers, as a practical example, heat balance of the water in the heat system at the end of a heat network section, exposed to temperature perturbation at the beginning of such section. The last section derives conclusions and covers limitations of this study and areas of further elaboration.

\section{BASE ANALYSIS}

\section{Obtaining a Set of Recurrence Relations}

Main downsides of known approaches to solving single differential equations or sets of such equations in applied mathematical modeling problems for physical processes include numerical methods with limited accuracy and stringent requirements for computational power for multidimensional sets, as well as limited application of the derived solutions in more sophisticated models. A direct analytical solution should be derived to eliminate such flaws.

A particular solution of set (1) is usually determined by the sequence of initial distributions of the parameters $y_{1}, \ldots, y_{N}$ with $x=0$ :

$$
\left\{\begin{array}{l}
y_{1}=y_{1}^{H} \\
y_{2}=y_{2}^{H} \\
y_{3}=y_{3}^{H} \\
\cdots \cdots \cdots \\
y_{N}=y_{N}^{H}
\end{array}\right.
$$


A set of recurrent integral solutions is the solution for the set of differential equations in (1).

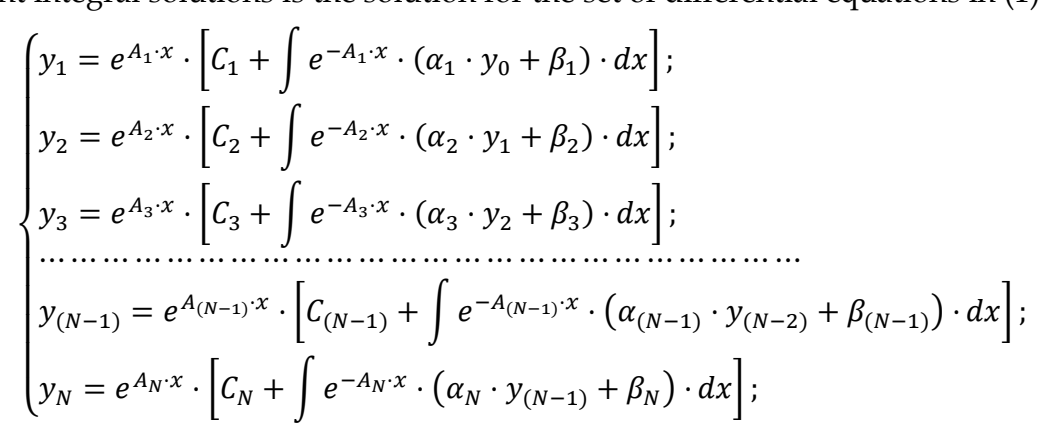

where $C_{1}, \ldots, C_{N}$ are integration constants. By substituting the initial distributions of the parameters $y_{1}, \ldots, y_{N}$ with $x=0$ (2), integration constants $C_{1}, \ldots, C_{N}$ are obtained:

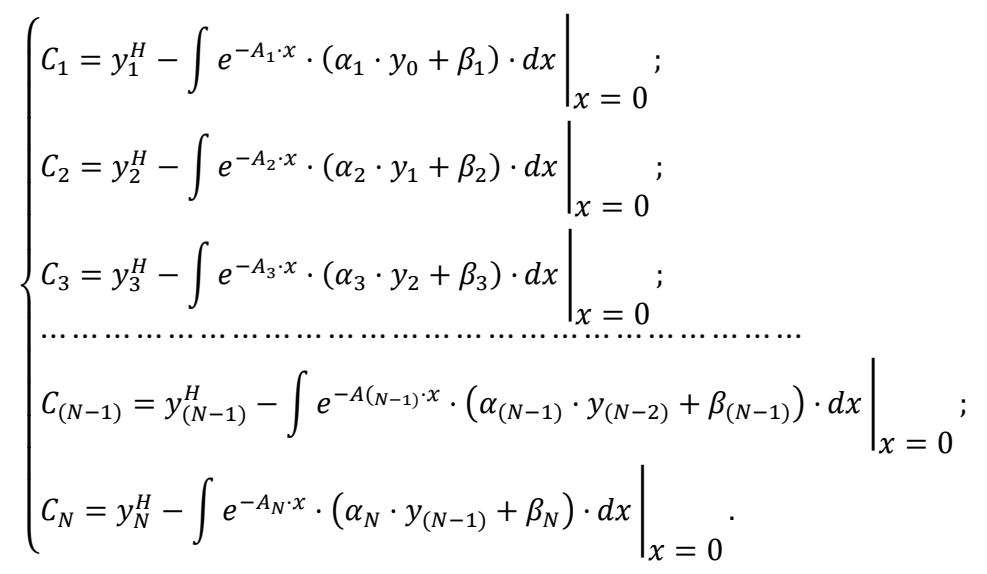

By substituting expressions (4) in equations (3), a sequence of recurrence relations is obtained:

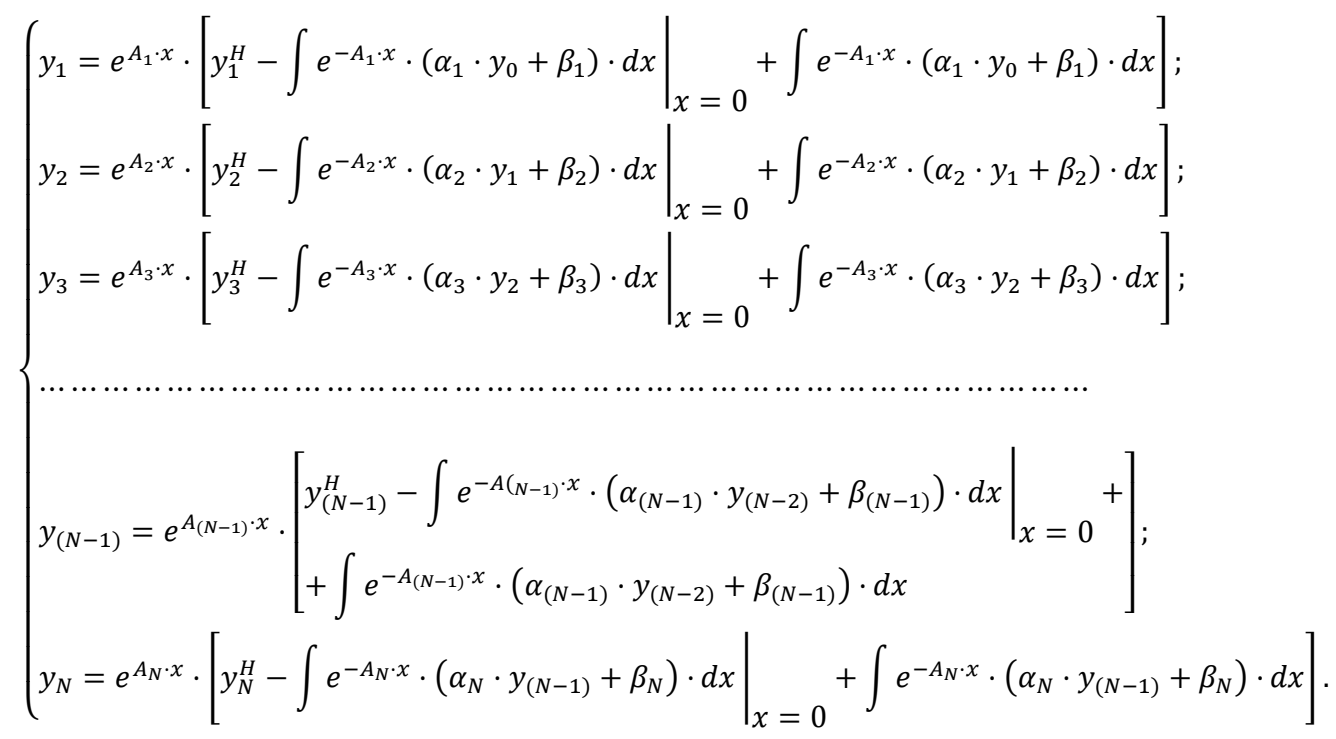

\section{Defining a Common Pattern for the Solutions}

To find a common pattern, the first three solutions are written down:

$$
y_{1}=e^{A_{1} \cdot x} \cdot\left[y_{1}^{H}-\frac{1}{0-A_{1}} \cdot\left(\alpha_{1} \cdot y_{0}+\beta_{1}\right)\right]+\frac{1}{0-A_{1}} \cdot\left(\alpha_{1} \cdot y_{0}+\beta_{1}\right) ;
$$




$$
\begin{aligned}
& y_{2}=e^{A_{2} \cdot x} \cdot\left[y_{2}^{H}-\left\{\begin{array}{l}
\frac{1}{A_{1}-A_{2}} \cdot\left(\alpha_{2} \cdot y_{1}^{H}-\alpha_{2} \cdot \frac{1}{0-A_{1}} \cdot\left(\alpha_{1} \cdot y_{0}+\cdot \beta_{1}\right)\right)+ \\
+\frac{1}{0-A_{2}} \cdot\left(\alpha_{2} \cdot \frac{1}{0-A_{1}} \cdot\left(\alpha_{1} \cdot y_{0}+\beta_{1}\right)+\beta_{2}\right)
\end{array}\right\}+\right] \\
& +e^{A_{1} \cdot x} \cdot\left[\frac{1}{A_{1}-A_{2}} \cdot\left(\alpha_{2} \cdot y_{1}^{H}-\alpha_{2} \cdot \frac{1}{0-A_{1}} \cdot\left(\alpha_{1} \cdot y_{0}+\beta_{1}\right)\right)\right]+ \\
& +e^{0 \cdot x} \cdot\left[\frac{1}{0-A_{2}} \cdot\left(\alpha_{2} \cdot \frac{1}{0-A_{1}} \cdot\left(\alpha_{1} \cdot y_{0}+\beta_{1}\right)+\beta_{2}\right)\right] \text {; }
\end{aligned}
$$

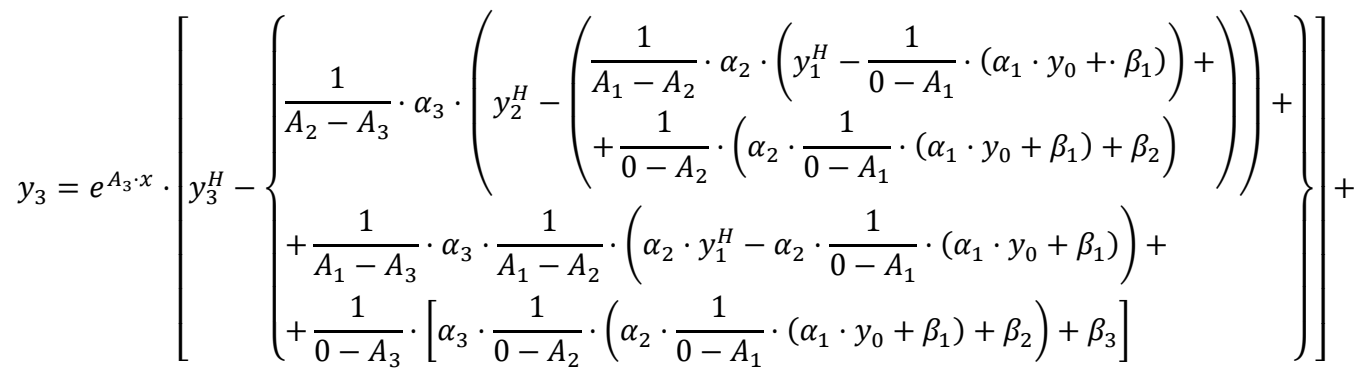

$$
\begin{aligned}
& +e^{A_{2} \cdot x} \cdot\left[\frac{1}{A_{2}-A_{3}} \cdot \alpha_{3} \cdot\left(y_{2}^{H}-\left(\begin{array}{l}
\frac{1}{A_{1}-A_{2}} \cdot \alpha_{2} \cdot\left(y_{1}^{H}-\frac{1}{0-A_{1}} \cdot\left(\alpha_{1} \cdot y_{0}+\cdot \beta_{1}\right)\right)+ \\
+\frac{1}{0-A_{2}} \cdot\left(\alpha_{2} \cdot \frac{1}{0-A_{1}} \cdot\left(\alpha_{1} \cdot y_{0}+\beta_{1}\right)+\beta_{2}\right)
\end{array}\right)\right)\right]+ \\
& +e^{A_{1} \cdot x} \cdot\left[\frac{1}{A_{1}-A_{3}} \cdot \alpha_{3} \cdot \frac{1}{A_{1}-A_{2}} \cdot e^{A_{1}} \cdot\left(\alpha_{2} \cdot y_{1}^{H}-\alpha_{2} \cdot \frac{1}{0-A_{1}} \cdot\left(\alpha_{1} \cdot y_{0}+\beta_{1}\right)\right)\right]+ \\
& +e^{0 \cdot x} \cdot \frac{1}{0-A_{3}} \cdot\left[\alpha_{3} \cdot \frac{1}{0-A_{2}} \cdot\left(\alpha_{2} \cdot \frac{1}{0-A_{1}} \cdot\left(\alpha_{1} \cdot y_{0}+\beta_{1}\right)+\beta_{2}\right)+\beta_{3}\right] \text {. }
\end{aligned}
$$

\section{Deriving a General Solution}

An easy way to present a general solution is:

$$
y_{N}=e^{A_{N} \cdot x} \cdot y_{N}^{H}+\sum_{S=0}^{N-1}\left[\left(e^{A_{S} \cdot x}-e^{A_{N} \cdot x}\right) \cdot \gamma_{S}^{P}\right],
$$

where $\gamma_{S}^{P}$ is a set of products of given constants $A_{1}, \ldots, A_{N}, \alpha_{1}, \ldots, \alpha_{N}, \beta_{1}, \ldots, \beta_{N}$ and the initial conditions.

Values $\gamma_{S}^{P}$ can be obtained by recurrent substitution and successive integration. Since successive integration of equations (3) gives successive products, such products can be interpreted in the form of a tree graph (Figure 1).

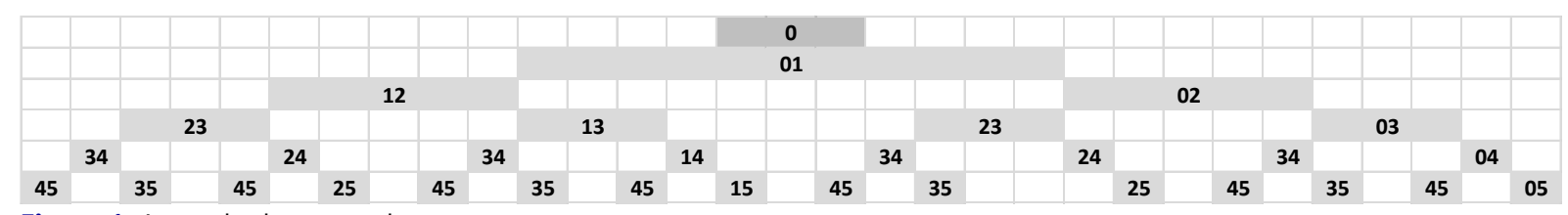

Figure 1. A standard tree graph

This stairstep presentation (Figure 2) gives a clear interpretation of a possible procedure of finding $\gamma_{S}^{P}$. Sum of products of the left-most multipliers $\psi_{S}^{P}$ can be denoted in the following way:

where:

$$
\psi_{S}^{P}=\frac{1}{A_{(P-1)}-A_{P}} \cdot \alpha_{P} \cdot \sum_{S=0}^{P-1} \gamma_{S}^{P-1},
$$

$P$ is layer number $[P=0, \ldots, N]$; and

$S$ is column number $[S=0, \ldots, N-1]$.

Then, $\gamma_{S}^{P}$ can be found in the following way: 


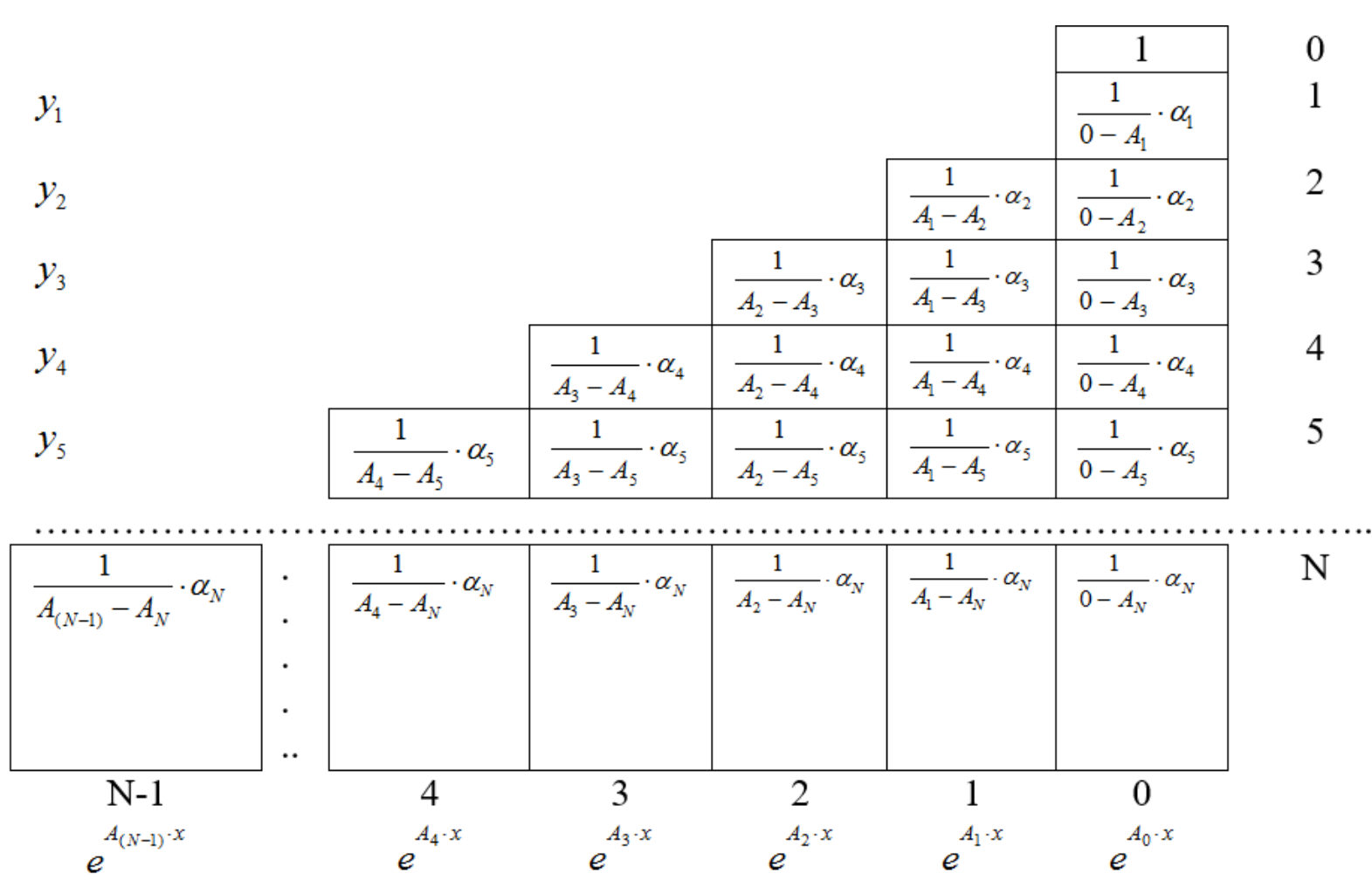

Figure 2. A stairstep tree graph

$$
\gamma_{S}^{P=N}=\psi^{P=S+1} \cdot \prod_{R=(S+1)+1}^{N}\left[\frac{1}{A_{S}-A_{R}} \cdot \alpha_{R}\right] .
$$

$\psi_{S}^{P}$ are not known in (11). Finding of these unknown quantities is reduced to defining a sum of products of tree graph weights (Figure 2) in a certain layer. $\psi_{S}^{P}$ can be written for some layers in the following way:

$$
\begin{gathered}
\psi_{0}^{1}=\frac{1}{0-A_{1}} \cdot \alpha_{1} ; \\
\psi_{1}^{2}=\frac{1}{0-A_{1}} \cdot \alpha_{1} \cdot \frac{1}{A_{1}-A_{2}} \cdot \alpha_{2} \\
\left.\psi_{3}^{3}=\frac{1}{0-A_{1}} \cdot \alpha_{1} \cdot \frac{1}{A_{1}-A_{2}} \cdot \alpha_{2}+\frac{1}{0-A_{1}} \cdot \alpha_{1} \cdot \frac{1}{0-A_{2}} \cdot \alpha_{2}\right] \cdot \frac{1}{A_{2}-A_{3}} \cdot \alpha_{3} ; \\
{\left[\begin{array}{l}
\frac{1}{0-A_{1}} \cdot \alpha_{1} \cdot \frac{1}{A_{1}-A_{2}} \cdot \alpha_{2} \cdot \frac{1}{A_{2}-A_{3}} \cdot \alpha_{3}+ \\
+\frac{1}{0-A_{1}} \cdot \alpha_{1} \cdot \frac{1}{A_{1}-A_{2}} \cdot \alpha_{2} \cdot \frac{1}{A_{1}-A_{3}} \cdot \alpha_{3}+ \\
+\frac{1}{0-A_{1}} \cdot \alpha_{1} \cdot \frac{1}{0-A_{2}} \cdot \alpha_{2} \cdot \frac{1}{A_{2}-A_{3}} \cdot \alpha_{3}+ \\
+\frac{1}{0-A_{1}} \cdot \alpha_{1} \cdot \frac{1}{0-A_{2}} \cdot \alpha_{2} \cdot \frac{1}{0-A_{3}} \cdot \alpha_{3}
\end{array}\right] .}
\end{gathered}
$$

In general, a sum of products of tree graph weights in a certain layer can be found in the following way: $P=1$ :

where $A_{0}=0$.

$$
\psi_{0}^{1}=\prod_{i=1}^{P}\left[\frac{1}{A_{1-1}-A_{i}} \cdot \alpha_{i}\right]
$$


$P=2$ :

$$
\psi_{1}^{2}=\left\{\begin{array}{l}
\prod_{i=1}^{P}\left[\frac{1}{A_{1-1}-A_{i}} \cdot \alpha_{i}\right]+ \\
+\sum_{j=1}^{P-1}\left(\prod_{i_{1}=1}^{j}\left[\frac{1}{A_{j-1}-A_{i_{1}}} \cdot \alpha_{i_{1}}\right] \cdot \prod_{i_{2}=i_{1}+1}^{P}\left[\frac{1}{A_{i_{2}-1}-A_{i_{2}}} \cdot \alpha_{i_{2}}\right]\right.
\end{array}\right.
$$

$P=3$ :

$$
\psi_{2}^{3}=\left\{\begin{array}{l}
\prod_{i=1}^{P}\left[\frac{1}{A_{1-1}-A_{i}} \cdot \alpha_{i}\right]+ \\
+\sum_{j=1}^{P-1}\left(\prod_{i_{1}=1}^{j}\left[\frac{1}{A_{j-1}-A_{i_{1}}} \cdot \alpha_{i_{1}}\right] \cdot \prod_{i_{2}=i_{1}+1}^{P}\left[\frac{1}{A_{i_{2}-1}-A_{i_{2}}} \cdot \alpha_{i_{2}}\right]\right)+ \\
+\sum_{j_{1}=1}^{P-2} \sum_{j_{2}=j_{1}+1}^{P-1}\left(\prod_{i_{1}=1}^{j_{1}}\left[\frac{1}{A_{j_{1}-1}-A_{i_{1}}} \cdot \alpha_{i_{1}}\right] \cdot \prod_{i_{2}=i_{1}+1}^{j_{2}}\left[\frac{1}{A_{i_{2}-1}-A_{i_{2}}} \cdot \alpha_{i_{2}}\right] \cdot \prod_{i_{3}=i_{2}+1}^{P}\left[\frac{1}{A_{j_{2}-1}-A_{i_{3}}} \cdot \alpha_{i_{3}}\right]\right)
\end{array}\right.
$$

$P=4:$

$$
\psi_{3}^{4}=\left\{\begin{array}{l}
\prod_{i=1}^{P}\left[\frac{1}{A_{i-1}-A_{i}} \cdot \alpha_{i}\right]+ \\
+\sum_{j=1}^{P-1}\left(\prod_{i_{1}=1}^{j}\left[\frac{1}{A_{j-1}-A_{i_{1}}} \cdot \alpha_{i_{1}}\right] \cdot \prod_{i_{2}=i_{1}+1}^{P}\left[\frac{1}{A_{i_{2}-1}-A_{i_{2}}} \cdot \alpha_{i_{2}}\right]\right)+ \\
\quad \sum_{j_{1}=1}^{P-2}\left(\prod_{j_{2}=j_{1}+1}^{P-1}\left[\frac{1}{A_{j_{1}-1}-A_{i_{1}}} \cdot \alpha_{i_{1}}\right] \cdot \prod_{i_{2}=i_{1}+1}^{j_{1}}\left[\frac{1}{A_{i_{2}-1}-A_{i_{2}}} \cdot \alpha_{i_{2}}\right] \cdot \prod_{i_{3}=i_{2}+1}^{P}\left[\frac{1}{A_{j_{2}-1}-A_{i_{3}}} \cdot \alpha_{i_{3}}\right]\right)+. \\
+\sum_{j_{1}=1}^{P-3} \sum_{j_{2}=j_{1}+1}^{P-2} \sum_{j_{3}=j_{2}+1}^{P-1}\left(\prod_{i_{1}=1}^{j_{1}}\left[\frac{1}{A_{j_{1}-1}-A_{i_{1}}} \cdot \alpha_{i_{1}}\right] \cdot \prod_{i_{2}=i_{1}+1}^{j_{3}}\left[\frac{1}{\prod_{i_{2}-1}-A_{i_{2}}} \cdot \alpha_{i_{2}}\right]\right. \\
\left.\prod_{i_{2}+1}\left[\frac{1}{A_{j_{2}-1}-A_{i_{3}}} \cdot \alpha_{i_{3}}\right] \cdot \prod_{i_{4}=i_{3}+1}^{P}\left[\frac{1}{A_{i_{4}-1}-A_{i_{4}}} \cdot \alpha_{i_{4}}\right]\right)
\end{array}\right.
$$

Then, generalization for $P=N$ gives:

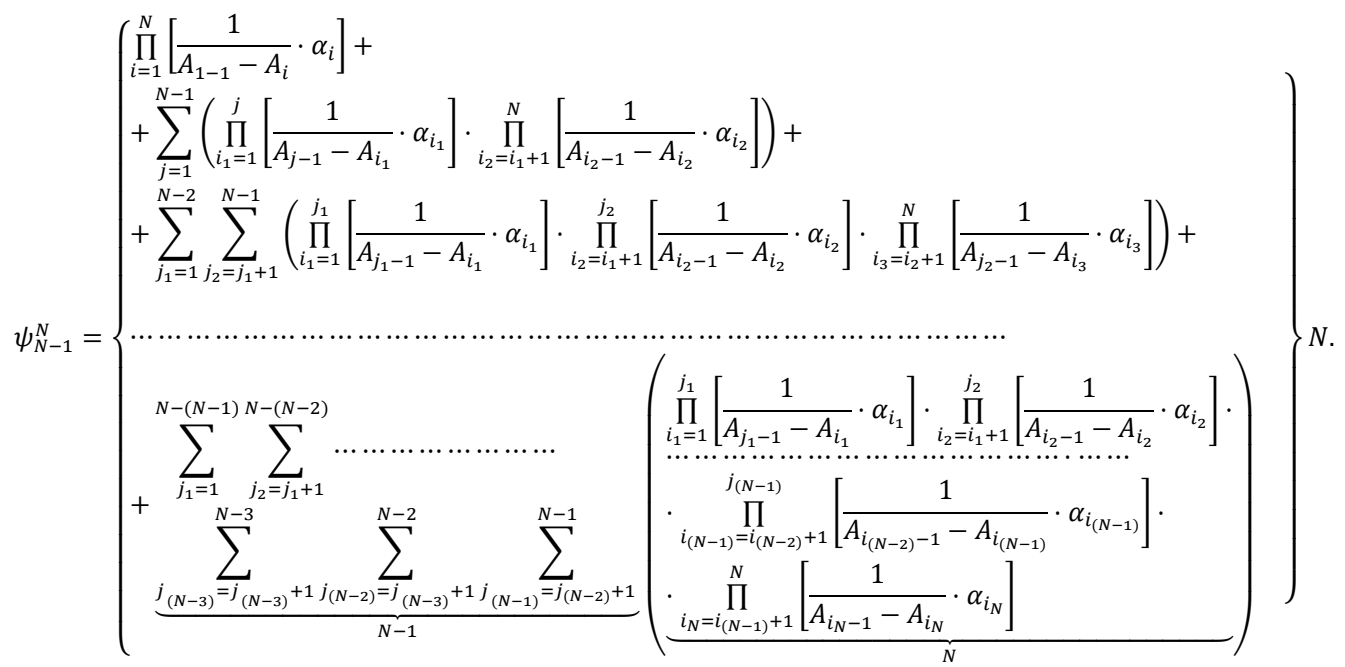

\section{Deriving a Solution in View of Constituents of Initial and Steady-states}

In order to define a general solution for (9) for layer $N, \gamma_{S}^{N}$ can be divided into three constituents:

$$
\gamma_{S}^{N}=\gamma_{S}^{N}\left(y_{0}\right)+\gamma_{S}^{N}\left(y^{H}\right)+\gamma_{S}^{N}(\beta) .
$$

Since extra $\beta_{i}$ is introduced for $\gamma_{S}^{N}(\beta)$ for each layer of a tree graph, a notation for a sum of products of tree graph weights in a certain layer must be introduced, while staring from the given layer and not from the first layer: 
$\boldsymbol{\psi}_{P=1}^{P=R}$ is a sum of products of tree graph weights in a certain layer $P=R$, starting from the first layer $P=1$ (general definition (20));

$\boldsymbol{\psi}_{P=1}^{P=R_{2}}$ is a sum of products of tree graph weights in a certain layer $P=R_{2}$, starting from the given layer $P=R_{1}$.

The sum of products of tree graph weights in a certain layer $P=N$, starting from the given layer $P=R_{1}$, can be defined in the following way:

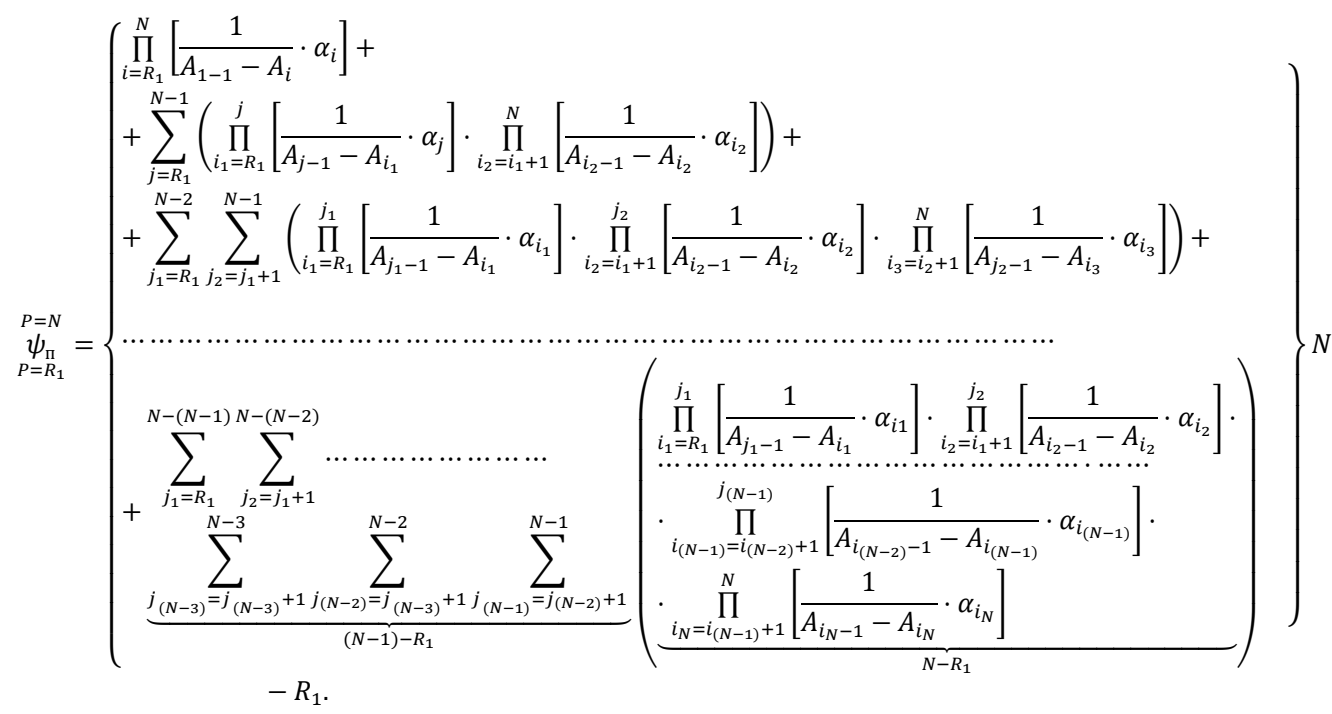

In order to define $\gamma_{S}^{N}\left(y^{H}\right)$, a definition of the sum of products of tree graph weights in a certain layer on the right side or on the left side must be introduced. $\boldsymbol{\psi}_{\boldsymbol{n}_{P}=R_{1}}^{P=N}$ The right side is defined according to (20) and differs from the left side by the presentation of the first products. The concept of right side is defined in a stairstep graph (Figure 2) for $\prod_{i=R_{1}}^{N}\left[\frac{1}{A_{1-1}-A_{i}} \cdot \alpha_{i}\right]=\prod_{i=R_{1}}^{N}\left[\frac{1}{0-A_{i}} \cdot \alpha_{i}\right]$ located on the right. To define a sum of products of tree graph weighs in a certain layer for the left side, the first products can be substituted by:

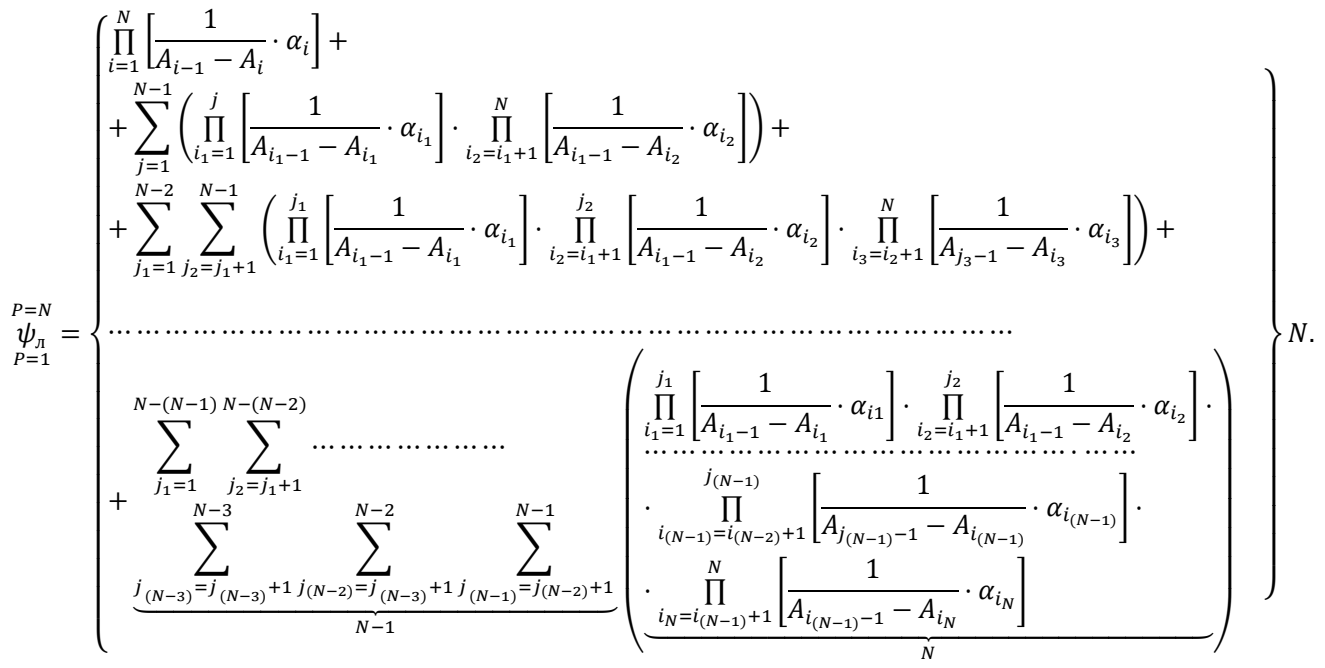

Particular solutions for equation (1) given in (3) are described by a partial sign alternation. A tree graph of successive products with $y_{0}$ in view of sign alternation is given in Figure 3 .

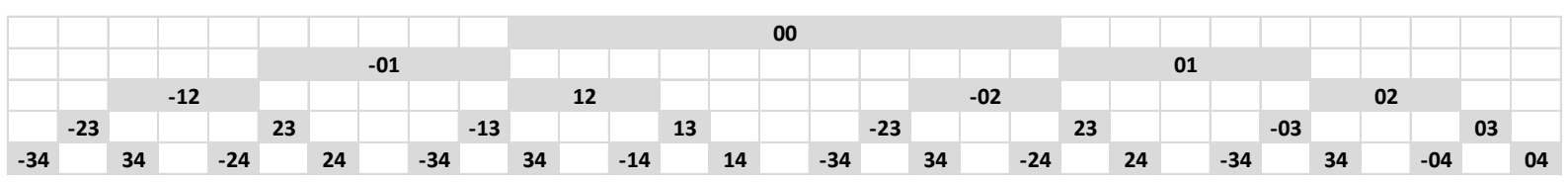

Figure 3. A standard tree graph with signs distributed 
The following notation can be introduced for further presentation:

$$
\prod_{i=n}^{N}[f(i)][F(i)]=\left\{\begin{array}{l}
f(i), \text { at } N=n ; \\
f(i) \cdot \prod_{i=n+1}^{N}[F(i)], \text { at } N>n .
\end{array}\right.
$$

Then, a sum of products of tree graph weights (Figure 3) in a certain layer with view to sign alternation and left-side bypass is:

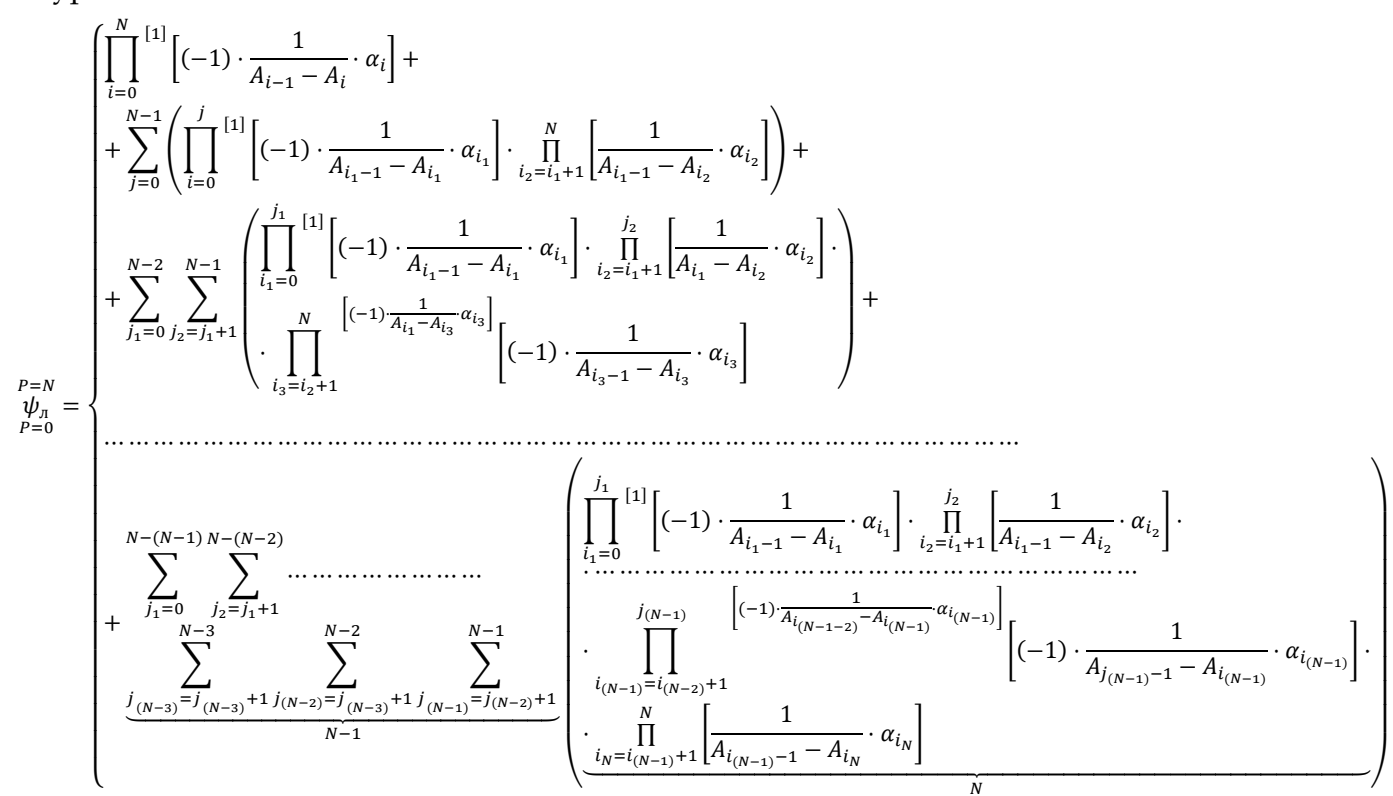

Considering (25), a sum of products of tree graph weights (Figure 3) in a certain layer with view to sign alternation and right-side bypass is:

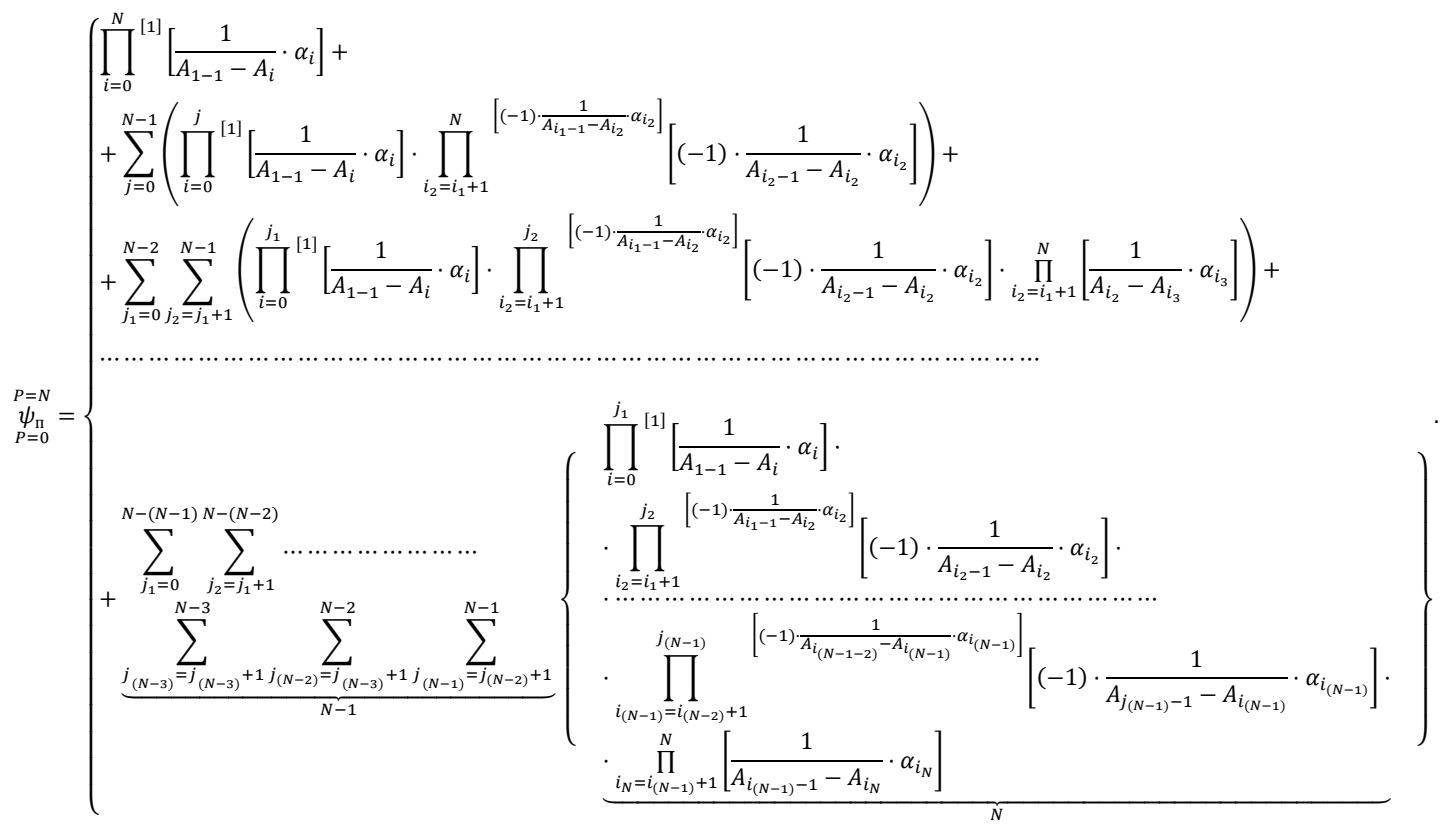

The sum of products of tree graph weights in a certain layer $P=N$, starting from given layer $P=R_{1}$, in view of signs and right-side bypass is defined in a way similar to (22): 


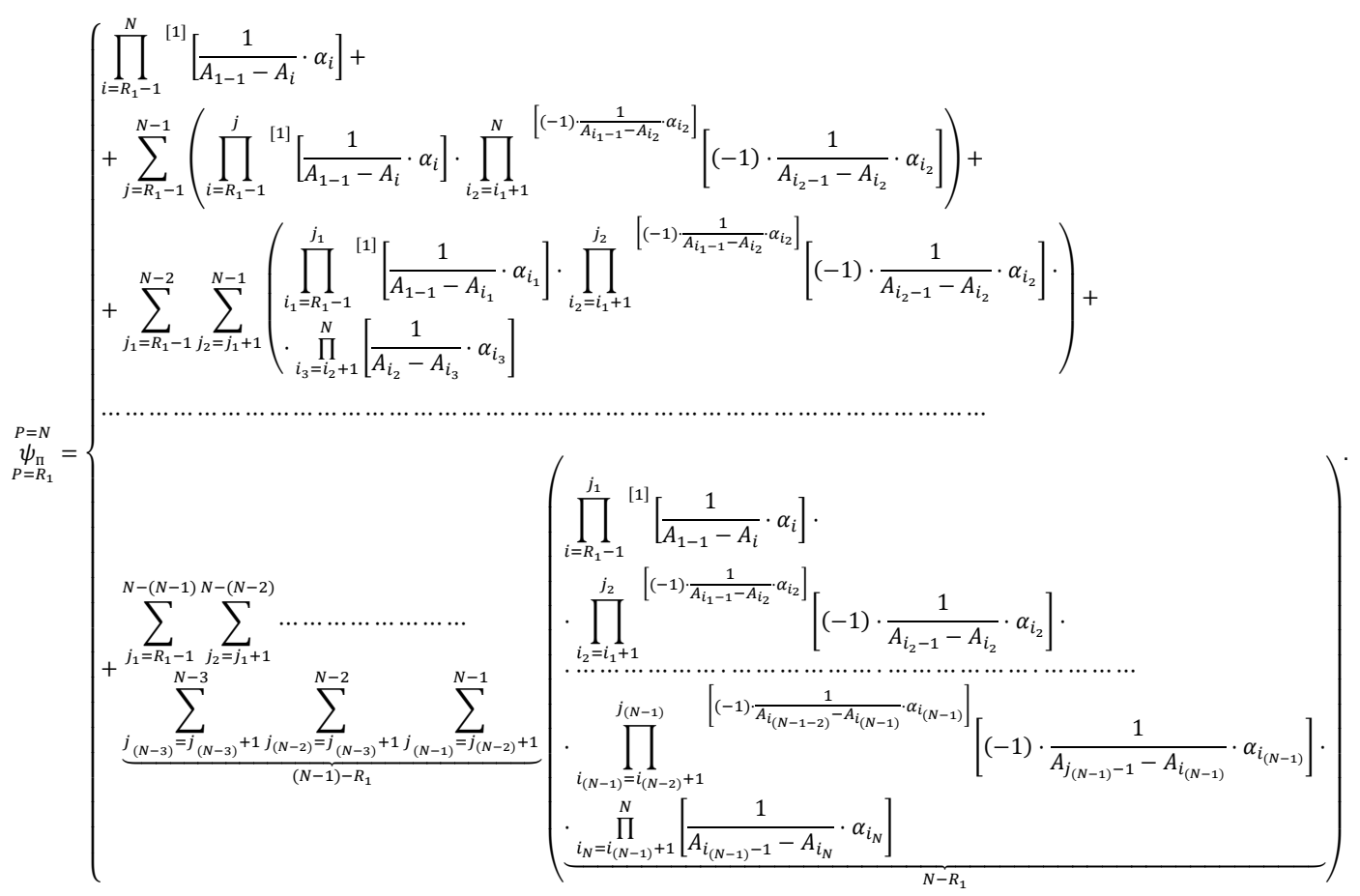

The condition of sign alternation (Figure 3) directs that the equation for $\gamma_{S}^{N}\left(y_{0}\right)$ (9) comprises $\boldsymbol{\psi}_{\boldsymbol{n}_{P=0}}^{S+1}$ as the sum of products of the tree graph weights in a certain layer solely with negative last multipliers, instead of all products. Extra notations must be introduced to account for this condition:

$\boldsymbol{\psi}_{\boldsymbol{n}_{P=R_{1}}}^{P=N_{(-)}}$is products of tree graph weights in a certain layer $P=N$, starting from given layer $P=R_{1}$, in view of signs and left-side bypass with the products having negative $(-)$ last multipliers:

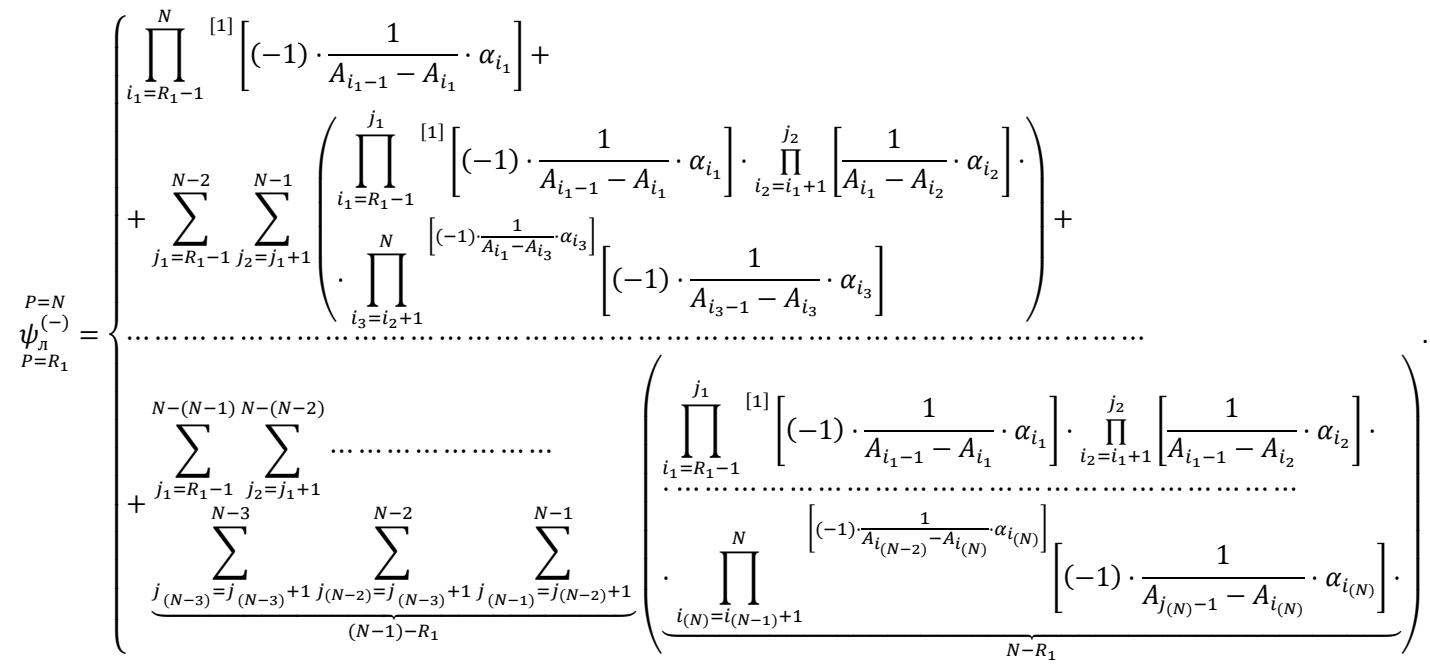

$\boldsymbol{\psi}_{\boldsymbol{n}_{P=R_{1}}}^{P=N_{(-)}}$is products of tree graph weights in a certain layer $P=N$, starting from given layer $P=R_{1}$, in view of signs and right-side bypass with the products having negative $(-)$ last multipliers: 


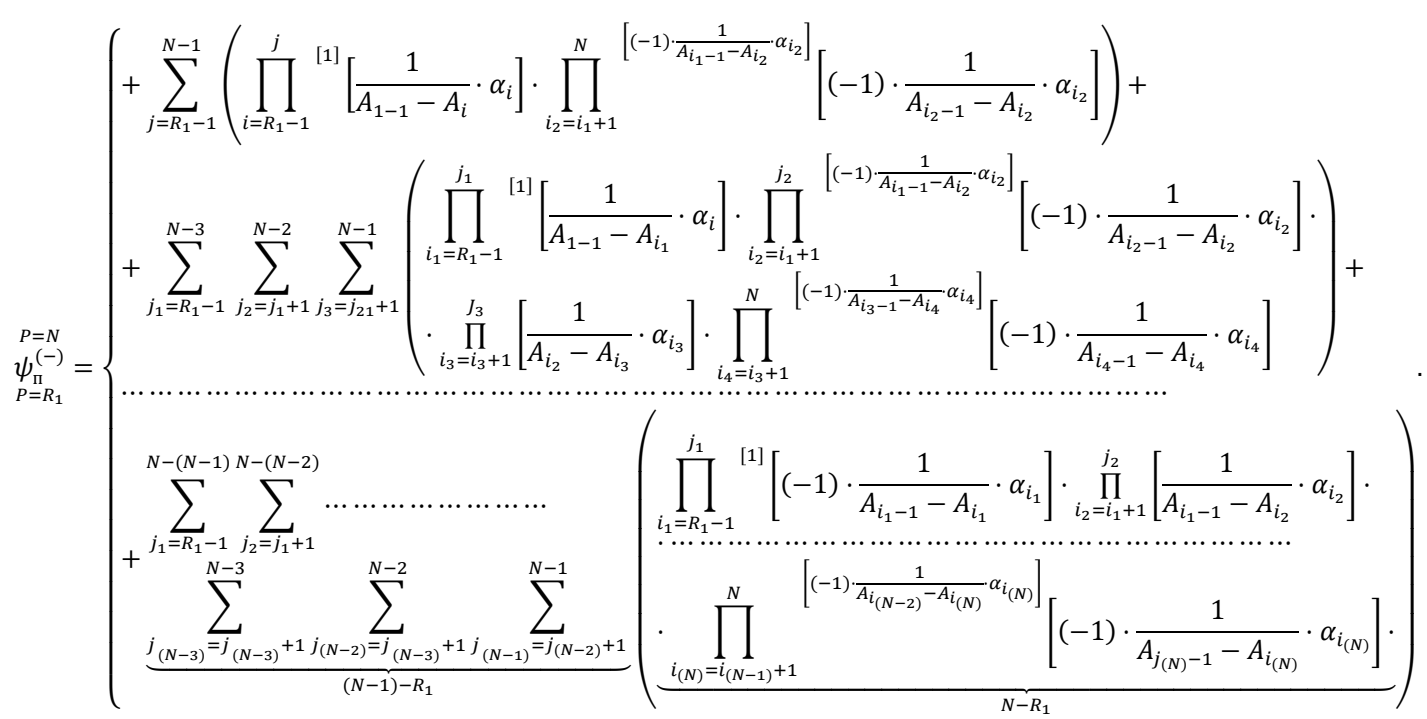

Then, considering (9) and (28-29), constituents $\gamma_{S}^{N}$ can be defined in the following way:

$$
\begin{aligned}
& \gamma_{S}^{N}\left(y_{0}\right)=y_{0} \cdot\left(\begin{array}{c}
S \\
\psi_{P=0}^{(-)} \\
P=0
\end{array} \prod_{R=S+1}^{N}\left[\frac{1}{A_{S}-A_{R}} \cdot \alpha_{R}\right]\right) ; \\
& \gamma_{S}^{N}(\beta)=\sum_{I=1}^{S}\left[\frac{\beta_{I}}{\alpha_{I}} \cdot \underset{P=I-1}{\psi_{\mathrm{I}}^{(-)}} \cdot \prod_{R=S+1}^{N}\left(\frac{1}{A_{S}-A_{R}} \cdot \alpha_{R}\right)\right] ;
\end{aligned}
$$

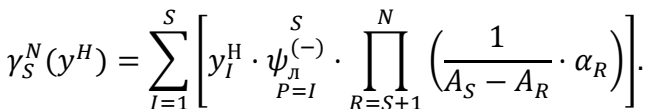

Considering (30-32), the solution of the initial set (1) is:

$$
y_{N}=e^{A_{N} \cdot x} \cdot y_{N}^{H}+\sum_{S=0}^{N-1}\left[\left(e^{A_{S} \cdot x}-e^{A_{N} \cdot x}\right) \cdot\left(\gamma_{S}^{N}\left(y_{0}\right)+\gamma_{S}^{N}\left(y^{H}\right)+\gamma_{S}^{N}(\beta)\right)\right] .
$$

One should mention a special case of constituents $\gamma_{S}^{N}$ with $S=0$ :

$$
\begin{gathered}
\gamma_{0}^{N}\left(y_{0}\right)=y_{0} \cdot \prod_{I=1}^{N}\left(\frac{1}{A_{0}-A_{I}} \cdot \alpha_{I}\right) ; \\
\gamma_{0}^{N}(\beta)=\sum_{I=1}^{S}\left[\frac{\beta_{I}}{\alpha_{I}} \cdot \prod_{R=I}^{N}\left(\frac{1}{A_{0}-A_{R}} \cdot \alpha_{R}\right)\right] ; \\
\gamma_{0}^{N}\left(y^{H}\right)=0 .
\end{gathered}
$$

\section{DISCUSSION}

The overall solution derived for an n-dimensional system matches known results for a case of a set that comprises of two or three differential equations [30]. This presentation of the solution is convenient for immediate use and for use in more complicated mathematical models. One should mention that the solution derived is reliable, provided denominators of coefficients $\frac{1}{A_{i}-A_{j}}$ are not zero. In other words, the following extra conditions must be imposed on the derived solutions:

$$
\left(A_{i}-A_{j}\right) \neq 0 \text {. }
$$

An example of practical application of set (1) can be heat balance of heat system water flow at the end of a heat network section exposed to temperature perturbation at the beginning of such section. This balance can be written down in the following way:

where:

$$
V_{1} \cdot \mathrm{c}_{\mathrm{P}} \cdot \rho_{\mathrm{B}} \cdot d t_{1}=-v_{1} \cdot \mathrm{c}_{\mathrm{P}} \cdot \rho_{\mathrm{B}} \cdot\left(t_{1}-t_{1}^{\mathrm{y}}\right) \cdot d \tau
$$

$c_{P}$ is heat system water capacitance $\left[\mathrm{KJ} / \mathrm{kg}^{\circ} \mathrm{C}\right]$;

$\rho_{B}$ is heat system water density $\left[\mathrm{kg} / \mathrm{m}^{3}\right]$; 
$t_{1}$ is water temperature at the end of a heat network section at a certain time point $d \tau\left[{ }^{\circ} \mathrm{C}\right]$;

$t_{1}^{y}$ is water temperature at the end of a heat network section at a certain time point $\tau \rightarrow \infty\left[{ }^{\circ} \mathrm{C}\right]$;

$V_{1}$ is heat network section volume $\left[\mathrm{m}^{3}\right]$; and

$v_{1}$ is volume water flow at a section $\left[\mathrm{m}^{3} / \mathrm{sec}\right]$.

Heat losses at the section can be accounted for by writing down a heat balance equation in steady-state:

$$
\left(t_{0}-t_{1}^{\mathrm{y}}\right) \cdot v_{1} \cdot \mathrm{c}_{\mathrm{P}} \cdot \rho_{\mathrm{B}}=K_{1} \cdot \pi \cdot l_{1} \cdot\left(1+\mu_{1}\right) \cdot\left(\bar{t}_{1}^{\mathrm{y}}-t_{\mathrm{H}}\right),
$$

where:

$t_{0}$ is temperature perturbation at the beginning of a heat network section $\left[{ }^{\circ} \mathrm{C}\right]$;

$\bar{t}_{1}{ }^{y}$ is mean heat system water temperature at a heat network section [ $\left.{ }^{\circ} \mathrm{C}\right]$;

$v_{1}$ is volume water flow at a section $\left[\mathrm{m}^{3} / \mathrm{sec}\right]$;

$\mu_{1}$ is coefficient of local heat losses of a heat network section;

$K_{1} \cdot \pi$ are linear heat losses; and

$l_{1}$ is piping length of a heat network section.

The solution of equation (38) relative to $t_{1}^{y}$ and in view of $\bar{t}_{1}^{y}=\frac{t_{1}^{y}+t_{0}}{2}$ is the following:

$$
t_{1}^{\mathrm{y}}=t_{0} \cdot \frac{2-\varepsilon_{\mathrm{TC} 1}}{2+\varepsilon_{\mathrm{TC} 1}}+2 \cdot t_{\mathrm{H}} \cdot \frac{\varepsilon_{\mathrm{TC} 1}}{2+\varepsilon_{\mathrm{TC} 1}}
$$

where $\varepsilon_{\mathrm{TC1}}=\frac{K_{1} \cdot \pi \cdot l_{1} \cdot\left(1+\mu_{1}\right)}{v_{1} \cdot c_{\mathrm{P}} \cdot \rho_{\mathrm{B}}}$ is a dimensionless number that describes heat losses through the heat insulation of the heat network section relative to the flow that passes through. Equation (39) will then be transformed into a set identical to (1):

$$
\left\{\begin{array}{l}
t_{1}^{\mathrm{y}}=t_{0} \cdot \frac{2-\varepsilon_{\mathrm{TC}(1)}}{2+\varepsilon_{\mathrm{TC}(1)}}+2 \cdot t_{\mathrm{H}} \cdot \frac{\varepsilon_{\mathrm{TC}(1)}}{2+\varepsilon_{\mathrm{TC}(1)}} \\
t_{2}^{\mathrm{y}}=t_{1}^{\mathrm{y}} \cdot \frac{2-\varepsilon_{\mathrm{TC}(2)}}{2+\varepsilon_{\mathrm{TC}(2)}}+2 \cdot t_{\mathrm{H}} \cdot \frac{\varepsilon_{\mathrm{TC}(2)}}{2+\varepsilon_{\mathrm{TC}(2)}} \\
\cdots \cdots \cdots \cdots \cdots \cdots \cdots \cdots \cdots \cdots \cdots \cdots \cdots \cdots \cdots \cdots \cdots \cdots \cdots \cdots \cdots \cdots \cdots \cdots \cdots \cdots \cdots \cdots \cdots \cdots \cdots \cdots \cdots \cdots \\
t_{n_{\mathrm{TC}}}^{\mathrm{y}}=t_{n_{\mathrm{TC}}-1}^{\mathrm{y}} \cdot \frac{2-\varepsilon_{\mathrm{TC}\left(n_{\mathrm{TC}}\right)}}{2+\varepsilon_{\mathrm{TC}\left(n_{\mathrm{TC}}\right)}}+2 \cdot t_{\mathrm{H}} \cdot \frac{\varepsilon_{\mathrm{TC}\left(n_{\mathrm{TC}}\right)}}{2+\varepsilon_{\mathrm{TC}\left(n_{\mathrm{TC}}\right)}} .
\end{array}\right.
$$

\section{CONCLUSION}

1. Contrary to well-known methods of addressing sets of first-order differential equations, this research produces a direct analytical dependence (34).

2. The solution produced integrates and differentiates easily, since it comprises of solely exponential factors.

3. Again, the solution can be used as a constituent of more sophisticated mathematical models of physical processes.

4. The solution for set (1) is constrained with extra condition $\left(A_{i}-A_{j}\right) \neq 0$.

5. This research gives an example of practical application of the solution to an $\mathrm{n}$-dimensional set of cooling sections of a heat network. Easy implementation of the direct analytical solution determines high practical value of the results.

6. Areas for further elaboration of this research can include practical problems of modeling physical processes that can be solved using the solution and derivation of set (1), which is not constrained with limiting condition (37).

\section{ACKNOWLEDGEMENTS}

This research has been done as part of the initiative for fundamental academic projects to fulfill the basic part of the governmental assignment by the Ministry of Education of the Russian Federation. 


\section{REFERENCES}

Bau, U., Braatz, A. L., Lanzerath, F., Herty, M., \& Bardow, A. (2015). Control of adsorption chillers by a gradient descent method for optimal cycle time allocation. International Journal of Refrigeration-Revue Internationale du Froid, 56, 52-64. doi:10.1016/j.ijrefrig.2015.03.026

Bég, O. A., Ali, N., \& Zaman, A. et al. (2016). Computational modeling of heat transfer in an annular porous medium solar energy absorber with the P1-radiative differential. Journal of the Taiwan Institute of Chemical Engineers, 66, 258-268. doi:10.1016/j.jtice.2016.06.034

Bolatturk, A. (2006). Determination of optimum insulation thickness for building walls with respect to various fuels and climate zones in Turkey. Appl Therm Eng, 26(11-12), 1301-9. doi:10.1016/j.applthermaleng.2005.10.019

Etter, D. M., Kuncicky, D., \& Moore, H. (2004). Introduction to MATLAB 7. Springer.

Gao, H., Chui, E., \& Runstedler, A. et al. (2010). Numerical investigation of plasma ignition process in a utility boiler. Proceedings of 6th International Workshop and Exhibition on Plasma Assisted Combustion (IWEPAC). Heilbronn, Germany, 13-15 September, 69.

Gholampour, M., \& Ameri, M. (2015). Design Considerations of Photovoltaic/Thermal Air Systems: Energetic and Exergetic Approaches. Journal of Solar Energy Engineering. Transactions of the ASME, 137(3). Article: 031005. doi:10.1115/1.4029107

Goryachikh, N. V., Batukhtin, A. G., \& Ivanov, S. A. (2010). Some Methods for Making Cogeneration Stations More Maneuverable. Thermal Engineering, 57(10), 892-896.

Hussain, M. I., Ali, A., \& Lee, G. H. (2016). Multi-module concentrated photovoltaic thermal system feasibility for greenhouse heating: Model validation and techno-economic analysis. Solar Energy, 135, 719-730. doi:10.1016/j.solener.2016.06.053

Kalema, T., Jóhannesson, G., Pylsy, P., \& Hagengran, P. (2008). Accuracy of Energy Analysis of Buildings: A Comparison of a Monthly Energy Balance Method and Simulation Methods in Calculating the Energy Consumption and the Effect of Thermal Mass. Journal of Building Physics, 32(2), 101-130. doi:10.1177/1744259108093920

Kaminski, K., \& Krzyzynski, T. (2016). Modeling and Simulation of the Solar Collector Using Different Approaches. Mechatronics: Ideas, Challenges, Solutions and Applications, 414, 131-151. doi:10.1007/978-3-319-26886-6_9

Karpenko, E. I., Rinchinov, A. P., Karpenko, Y. E., Bass, M. S., \& Batukhtin, S. G. (2016). The results of the tests of experimental-industrial plasma-cyclone installation. Promyshlennaya Energetika, 4, 24-27.

Karpenko, E. I., \& Trusov, B. G. (1995). A Comparative Analysis of Plasma and Fire Technologies of Pulverized Coal Ignition, Combustion and Gasification Using a Mathematical Model of Chemically Non-equilibrium System. Thermophysics and Aeromechanics, 2(23), 245-250.

Khelifa, A., Touafek, K., \& Ben M. (2015). Approach for the modelling of hybrid photovoltaic-thermal solar collector. IET Renewable Power Generation, 9(3), 207-217. doi:10.1049/iet-rpg.2014.0076

Khelifa, A., Touafek, K., Ben Moussa, H., \& Tabet, I. (2016). Modeling and detailed study of hybrid photovoltaic thermal (PV/T) solar collector. Solar Energy, 135, 169-176. doi:10.1016/j.solener.2016.05.048

Kicsiny, R. (2017). Grey-box model for pipe temperature based on linear regression. International Journal of Heat and Mass Transfer, 107, 13-20. doi:10.1016/j.ijheatmasstransfer.2016.11.033

Kicsiny, R. (2016). Improved multiple linear regression based models for solar collectors. Renewable Energy, 91, 224232. doi:10.1016/j.renene.2016.01.056

Kicsiny, R. (2014). New delay differential equation models for heating systems with pipes. Int. J. Heat Mass Transfer, 79, 807-815. doi:10.1016/j.ijheatmasstransfer.2014.08.058

Li, H., \& Chen, Z. (2008). Overview of different wind generator systems and their comparisons. IET Renewable Power Generation, 2(2), 123-138. doi:10.1049/ iet-rpg:20070044

Messerle, V. E., Karpenko, E. I., \& Ustimenko, A. B. (2014). Plasma Assisted Power Coal Combustion in the Furnace of Utility Boiler: Numerical Modelling and Full-Scale Test. Fuel, 126, 294-300. doi:10.1016/j.fuel.2014.02.047

Messerle, V. E., Karpenko, E. I., Ustimenko, A. B., \& Lavrichshev, O. A. (2013). Plasma preparation of coal to combustion in power boilers. Fuel Processing Technology, 107, 93-98. doi:10.1016/j.fuproc.2012.07.001

Messerle, V. E., Mosse, A. L., \& Ustimenko, A. B. (2016). Municipal Solid Waste Plasma Processing: Thermodynamic Computation and Experiment. IEEE Transactions on Plasma Science, 99, 1-6. doi:10.1109/TPS.2016.2601107

Messerle, V. E., Ustimenko, A. B., \& Lavrichshev, O. A. (2016), Comparative study of coal plasma gasification: Simulation and experiment. Fuel, 164, 172-179. doi:10.1016/j.fuel.2015.09.095 
Polyanin, A. D., \& Zaitsev, V. F. (2003). Handbook of Exact Solutions for Ordinary Differential Equations, 2nd Edition, Chapman \& Hall/CRC, Boca Raton.

Romero, J. C., \& Linares, P. (2014). Exergy as a global energy sustainability indicator. A review of the state of the art. Renewable and Sustainable Energy Reviews, 33, 427-442. doi:10.1016/j.rser.2014.02.012

Saleh, A. M., Mueller, D. W., \& Abu-Mulaweh, H. I. (2015). Flat-Plate Solar Collector in Transient Operation: Modeling and Measurements. Journal of Thermal Science and Engineering Applications, 7. doi:10.1115/1.4028569.

Sheng, S., \& Tu, Z. C. (2013). Universality of energy conversion efficiency for optimal tight-coupling heat engines and refrigerators. Journal of Physics A: Mathematical and Theoretical, 46(40), 402001. doi:10.1088/1751$8113 / 46 / 40 / 402001$

Smith, E., Koolnapadol, N., \& Promvonge, P. (2012). Heat transfer behavior in a square duct with tandem wire coil element insert. Chin. J. Chem. Eng., 20, 863-869. wos:000311472200008

Stepanov, V., Starikova, N., \& Stepanova, T. (2000). Indices for estimation of energy conservation in space heating. Energy and Buildings, 31(3), 189-193. doi:10.1016/S0378-7788(99)00013-4

Stevanovic, V. D., Zivkovic, B., Prica, S., Maslovaric, B., Karamarkovic, V., \& Trkulja, V. (2009). Prediction of thermal transients in district heating systems. Energy Convers. Manage, 50, 2167-2173. doi:10.1016/j.enconman.2009.04.034

Thianpong, C., Yongsiri, K., Nanan, K., \& Eiamsa-ard, S. (2012). Thermal performance evaluation of heat exchangers fitted with twisted-ring turbulators. Int. Commun. Heat Mass Transf., 39, 861-868. doi:10.1016/j.icheatmasstransfer.2012.04.004

Torío, H., Angelotti, A., \& Schmidt D. (2009). Exergy analysis of renewable energy-based climatisation systems for buildings: a critical view. Energy and Buildings, 41(3), 248-271.

Valero, A. (2006). Exergy accounting: capabilities and drawbacks. Energy, 31(1), 164-180. doi:10.1016/j.energy.2004.04.054

\section{http://www.ejmste.com}

